\title{
Simulações virtuais de experimentos históricos para o ensino da Teoria Eletrofraca ${ }^{+}$
}

Márcia da Costa ${ }^{1}$

Universidade Federal do Espírito Santo

Alegre - ES

Murilo Crivellari Camargo ${ }^{1}$

Yago Henrique Pereira ${ }^{l}$

Irinéa de Lourdes Batista ${ }^{1}$

Jacques Duílio Brancher ${ }^{1}$

Universidade Estadual de Londrina

Londrina - PR

\section{Resumo}

Este artigo apresenta um conjunto de simulações virtuais elaboradas com base em experimentos históricos que contribuíram para o processo de unificação das interações eletromagnética e fraca, bem como sugestões para utilização em sala de aula. Foram desenvolvidas simulações de três experimentos que vão desde o início do questionamento que levou ao desenvolvimento da Teoria Eletrofraca até o processo de detecção das partículas mediadoras da interação fraca, previstas teoricamente. As simulações foram programadas com Unity $3 D$ e todo o processo de elaboração contou com o apoio de uma equipe multidisciplinar com integrantes da área de Ensino, Física, História e Filosofia da Ciência, Design e Ciência da Computação. Essa colaboração foi essencial para obter um recurso didático que refletisse as competências das áreas dos especialistas e que pode ser um instrumento frutífero para a aprendizagem de conceitos e procedimentos experimentais relacionados a Teoria Eletrofraca, desde que explorado em abordagens didáticas planejadas e estruturadas de acordo com um referencial teórico adequado ao contexto de aplicação. Desse modo, este

\footnotetext{
${ }^{+}$Virtual Simulations of Historical Experiments for the teaching of the Electroweak Theory

* Recebido: abril de 2020. Aceito: junho de 2020.

${ }^{1}$ E-mails: marciarscosta@hotmail.com; murilocrivellaric@gmail.com; yago.henriquep@gmail.com; irinea2009@gmail.com; jacques.brancher@gmail.com
} 
trabalho também apresenta uma sugestão de Unidade Didática para exploração das simulações, baseada em princípios da teoria da Aprendizagem Significativa e do Ensino Investigativo.

Palavras-chave: Simulações Virtuais; Experimentos Históricos; Ensino Investigativo; Teoria Eletrofraca.

\begin{abstract}
This paper presents a set of virtual simulations based on historical experiments that contributed to the process of unification of the electromagnetic and weak interactions, as well as suggestions for use in the classroom. Simulations of three experiments were developed, ranging from the beginning of the questioning that led to the development of the Electroweak Theory to the detection process of the mediating particles in the weak interaction, theoretically predicted. The simulations were programmed with Unity $3 D$ and the whole elaboration process was supported by a multidisciplinary team with members from the following fields: Science Education, Physics, History and Philosophy of Science, Design and Computer Science. This collaboration was essential to achieve didactical resources that reflect the ability of all of those fields and, at the same time, that can be a fruitful instrument for the learning of experimental concepts and procedures related to the Electroweak Theory, since that it is used in educational approaches planned and structured according to a theoretical suited to application context. Thus, this work also presents a Didactical Unit suggestion for exploring the simulations, based on the principles of the theory of Meaningful
\end{abstract} Learning and Inquiry Learning.

Keywords: Virtual Simulations; Historical Experiments; Inquiry Learning; Electroweak Theory.

\title{
I. Introdução
}

$\mathrm{O}$ estudo e ensino de temas relacionados à Física Moderna Contemporânea (FMC) não é uma tarefa trivial, pois envolve fenômenos abstratos, idealizados, de sofisticada físicomatematização e aparatos experimentais de alto custo financeiro. Ao tratar da Física de Partículas, fala-se de partículas elementares, elétrons, glúons, bósons mediadores, bósons de Higgs, correntes neutras, interações fundamentais na matéria, enfim, conceitos e assuntos que podem não ficar claros perante uma abordagem tradicional de ensino. Além disso, ao procurar 
uma abordagem experimental, em muitos casos os professores se deparam com experimentos feitos em grandes laboratórios e com equipamentos sofisticados, caros e, em alguns casos, aparatos de grandes magnitudes construtivas, inclusive inexistentes em vários países. Isso dificulta o desenvolvimento e aplicação de uma abordagem para sala de aula.

Assim, uma das alternativas é a utilização de simulações virtuais, que pode tornar o processo de ensino e aprendizagem mais interativo e menos abstrato (MEDEIROS; MEDEIROS, 2002; SMETANA; BELL, 2012). Elas possibilitam que fenômenos e experimentos sejam simulados de maneira a oferecer para os alunos uma forma de interação com o objeto de estudo e com isso dar a eles a oportunidade de testarem hipóteses, aprenderem com seus erros e seguirem o processo de aprendizagem de acordo com seu nível de aproveitamento.

Além do mais, as simulações conseguem tornar esses conceitos e assuntos menos abstratos. Sempre lembrando que uma simulação virtual não consegue abranger todas as variáveis e complexidades de um fenômeno ou experimento real, mas, na forma de modelos com objetivos didáticos, consegue permitir a observação de situações virtuais e representações de fenômenos, uma vez que a observação real por meio da experimentação se mostra inviável ou impossível de acontecer. Ainda, possibilita uma mudança no papel desempenhado pelo aluno, pois as simulações exigem dele respostas e tomadas de decisões (CARDOSO; DICKMAN, 2012; FIGUEIRA, 2005).

Portanto, este artigo tem o objetivo de apresentar alternativas para o ensino de tópicos de FMC, no Ensino Superior, no formato de simulações de experimentos históricos e também sugestões para sua aplicação em sala de aula. Os experimentos históricos foram escolhidos, dentre as estratégias de inserção de História e Filosofia da Ciência (HFC), por se tratar de um recurso que engloba tanto o enfoque histórico quanto a experimentação, ambas abordagens contextualizadoras, articuladoras e integradoras. Esse enlace possui potencialidade de criar estímulo, motivação e desafios e, com isso, aprimorar situações de ensino e criar uma facilitação de aprendizagem em Ciências, especialmente na Física. Partindo de pressupostos diferentes, os dois enfoques têm o mesmo objetivo: transformar as aulas em ambientes que promovam a aprendizagem de forma não-mecânica, proporcionando a argumentação e o protagonismo de estudantes (BATISTA, 2004; SOUZA; SILVA; ARAÚJO, 2014; HEERING; WITTJE, 2012)

A Teoria Eletrofraca ${ }^{2}$ foi escolhida, entre os tópicos de FMC, por se tratar de uma temática que envolve o processo de unificação de duas das interações fundamentais da natureza e ter sido um passo significativo para um essencial entendimento da natureza da matéria e para o que hoje se conhece como Modelo Padrão da Física de Partículas. Dessa maneira, esses são temas que deveriam fazer parte do currículo universitário, uma vez que Sacristán (2000, p.37) afirma que, "no currículo universitário se destaca a adequação dos

\footnotetext{
${ }^{2}$ Uma Composição Histórica do processo de desenvolvimento dessa teoria pode ser consultada em Costa (2019), em cujo trabalho são apresentados detalhadamente todos os experimentos simulados virtualmente.
} 
currículos ao progresso da ciência, de diversos âmbitos do conhecimento e da cultura, e à exigência do mundo profissional”. Logo, a presença de temas de Física de Partículas é relevante nos currículos dos cursos de Licenciatura em Física, pois é um assunto de FMC, está presente no cotidiano dos alunos para os quais os futuros professores lecionarão, são temas relacionados com o progresso da ciência e também fazem parte da cultura atual.

Convém mencionar que as simulações aqui apresentadas são parte dos resultados de uma pesquisa de doutorado e passaram por avaliações de pares e de usuários, o que possibilitou serem aprimoradas e que fosse possível falar a respeito de suas potencialidades para situações de aprendizagem, entre as quais pode-se citar a boa aceitação de estudantes e indícios de aprendizagem significativa em relação aos conhecimentos científicos e a respeito de seu processo de elaboração.

\section{Simulação virtual de experimentos históricos no Ensino de Física}

De acordo com Heering e Wittje (2012), os experimentos são essenciais para uma educação científica e têm desempenhado um papel relevante no Ensino de Ciências desde o século XVIII. Assim, os experimentos históricos podem ser considerados como uma oportunidade para associar os benefícios da História da Ciência e das atividades experimentais em sala de aula. Essa combinação tem a vantagem de envolver tanto os estudantes que se interessam pelos relatos históricos como aqueles que preferem as atividades experimentais (SOUZA; SILVA; ARAÚJO, 2014).

Por experimento histórico, deve-se entender "toda e qualquer tentativa bem-sucedida em estabelecer um marco de referência conceitual e/ou metodológica na definição e/ou solução de um determinado problema específico" (RIBEIRO JUNIOR; CUNHA; LARANJEIRAS, 2012, p. 4602-1). Também pode ser interpretado como experiências que surgem a partir do estudo da Ciência do passado (CHANG, 2011).

Chang (2011) elenca possíveis tipologias de experimentos históricos. Existem dois tipos, que podem se qualificar como "replicação": um deles se preocupa com a reprodução mais fiel possível de um instrumento histórico, enquanto o outro dá mais ênfase para a reprodução fiel dos fenômenos físicos alcançados pelo experimento. Além desses, o autor cita o caso da extensão do experimento, na qual o estudante age motivado pela curiosidade de testar novas hipóteses e pode chegar a novas conclusões. Uma quarta tipologia pode ser definida pelas reconstruções históricas, descritas por Metz e Stinner (2007) como uma abordagem dos experimentos históricos que é guiada por uma narrativa histórica, na qual os estudantes têm a oportunidade de interagir com a narrativa por meio de experimentos elaborados por eles mesmos com materiais alternativos e de baixo custo.

No entanto, independente da tipologia adotada, entende-se que as dificuldades de replicação real de um experimento histórico podem ser variadas, indo desde a falta de informações precisas nos documentos históricos até a falta de recursos e técnicas utilizadas nos experimentos originais. Deste modo, para amenizar a falta de informações precisas em 
artigos, é necessário que o investigador tenha acesso a várias fontes de informação, desde os artigos originais até fontes secundárias que possam apresentar detalhamentos, fotos ou quaisquer outros registros que possam auxiliar na elucidação de todo o procedimento experimental (CHANG, 2011; HEERING, 2005).

Uma alternativa para resolver a falta de recursos e técnicas artesanais para confecção dos instrumentos experimentais é a simulação virtual do processo. Assim, se mantém a representação fidedigna do procedimento e, além do mais, acrescenta a possibilidade de que o recurso seja utilizado por vários estudantes ao mesmo tempo, em qualquer lugar, o que não seria possível com replicações reais (RIBEIRO JUNIOR; CUNHA; LARANJEIRAS, 2012).

Além disso, a partir de nossas pesquisas, consideramos necessária a elaboração de simulações considerando aspectos de teorias de aprendizagem para que se tornem recursos didáticos efetivamente inovadores e eficientes para a aprendizagem dos estudantes. Um exemplo é a Teoria de Aprendizagem Significativa, que sugere a consideração de princípios como: conhecimentos prévios dos estudantes, organização sequencial, diferenciação progressiva, reconciliação integradora, recursividade e consolidação dos conteúdos. Ainda, por se tratar de simulações de experimentos, pode-se utilizar o V de Gowin como um instrumento auxiliar no desenvolvimento e avaliação das atividades (AUSUBEL, 2003; GOWIN; ALVAREZ, 2005).

Neste trabalho foram consideradas características das tipologias definidas por Chang (2011) e Metz e Stinner (2007), segundo os quais os experimentos históricos reproduzidos podem representar, da forma mais fiel possível, os experimentos originais e/ou os fenômenos físicos por eles abordados. Além de serem auxiliados por uma construção textual histórica que permite a interação do estudante com o contexto da experimentação original que, nesse caso, se desenvolve com a simulação virtual.

Ensinar e aprender Física, tanto nas escolas como em universidades, não é uma tarefa fácil e várias são as causas, segundo Medeiros e Medeiros (2002). Um dos motivos é o fato de que essa disciplina trabalha com vários conceitos, dos quais muitos são abstratos, fazendo com que a Matemática se torne uma ferramenta essencial no desenvolvimento dessa Ciência. Além do mais, ela estuda fenômenos ou conceitos que, frequentemente, estão fora do alcance dos sentidos biológicos do ser humano, como por exemplo: partículas subatômicas, corpos com altas velocidades, entre outros processos dotados de grande complexidade. E isso, quando abordado com métodos de ensino desajustados das teorias de aprendizagem recentes, muitas vezes faz com que os estudantes se sintam entediados e perdidos com o estudo da Física.

Os resultados das pesquisas em Ensino de Física mostram que uma abordagem tradicional de "quadro e giz" pode não ser suficiente para motivar ou responder à curiosidade da maioria dos estudantes, tendo em vista que eles aprendem individualmente e à sua maneira, nem todos ao mesmo tempo e com as mesmas metodologias. No caso específico da disciplina de Física, existem conteúdos com alto grau de abstração, idealização e modelação que exigem 
mais do que uma abordagem oral e tradicional para que sejam compreendidos. Assim, as simulações virtuais de experimentos na Física, construídas com os cuidados teóricometodológicos já mencionados, se configuram como uma alternativa para tornar o ensino de Física mais atrativo, interessante e compreensível, uma vez que podem permitir aos alunos a observação de sistemas complexos que teriam dificuldades em imaginar apenas escutando o professor ou lendo textos. Dessa forma, a exploração de simulações pode ajudar os alunos a estruturarem esses sistemas complexos em sua mente ao invés de apenas memorizá-los (CARDOSO; DICKMAN, 2012; FIOLHAIS; TRINDADE, 2003; TOVAL; FLORES, 1987). Além disso, de acordo com uma revisão abrangente e crítica da literatura, a respeito das simulações no ensino de ciências, Smetana e Bell (2012) sugerem que as simulações virtuais são eficientes para promover o aprendizado de conceitos, alteração conceitual e desenvolvimento de habilidades processuais em aprendizes.

Martins, Fiolhais e Paiva (2003) defendem o uso das simulações virtuais pelo fato de aumentarem a atratividade das aulas e estimularem a aprendizagem dos alunos, mesmo considerando que elas não substituem as atividades experimentais. Porém, uma de suas potencialidades é complementar as atividades práticas, uma vez que nem sempre é possível realizar experimentos de determinados conteúdos. Assim, as simulações podem permitir a visualização de aspectos teóricos que não podem ser observados experimentalmente, como é o caso da representação de campos elétricos e magnéticos variando em uma onda eletromagnética, por exemplo.

As simulações virtuais são abordadas na literatura científica pelo menos há quatro décadas. Elas podem ser utilizadas no contexto científico e escolar, oferecendo alternativas para a resolução de problemas. São úteis na educação científica por facilitarem a aprendizagem de conceitos e processos e, quando projetadas adequadamente podem ajudar o aluno a levantar hipóteses, prever o curso e os resultados de determinadas ações, entender causas e consequências, explorar efeitos da modificação de parâmetros preliminares, avaliar ideias, obter insights e estimular o pensamento crítico (PSYCHARIS, 2011).

No âmbito científico, elas assumem um papel mais relevante do que o de uma ferramenta, constituindo uma nova forma de produção científica. Esse novo modo de produzir conhecimento científico expandiu o número de fenômenos que podem ser modelados e também aumentou significativamente a capacidade de testar hipóteses de modelos que são inviáveis de testes reais (GRECA; SEOANE; ARRIASSECQ, 2014).

Dentre as vantagens do uso de simulações virtuais para o ensino de Física, já listados na literatura, acrescenta-se a possibilidade de exploração de noções a respeito do trabalho dos cientistas. As simulações podem proporcionar discussões a respeito da construção do conhecimento científico, como é o caso da simulação de experimentos históricos, que fornece possibilidades de interação com experimentos considerados relevantes, segundo cada enfoque histórico construído, nos processos de construção dos conhecimentos científicos e que, antes disso, só podiam ser descritos por vídeos, imagens e textos. Desse modo, podem possibilitar 
habilidades inerentes ao raciocínio científico, ajudando estudantes a desenvolverem habilidades estáveis de raciocínio e tomada de decisão baseadas no conhecimento científico (DEVELAKI, 2017).

Além do mais, a reprodução de experimentos históricos, de acordo com Souza, Silva e Araújo (2014), apresenta várias possibilidades de exploração de perspectivas epistemológicas e metodológicas, pois o processo de reconstrução do experimento, o levantamento de hipóteses, as propostas elaboradas para resolver os problemas e a análise dos resultados obtidos mostram a complexidade do conhecimento científico e o papel dos experimentos.

Desse modo, as simulações virtuais de experimentos históricos caracterizam-se como alternativas para o desenvolvimento de atividades investigativas. $\mathrm{O}$ ensino investigativo é uma estratégia didática utilizada para elaborar sequências de atividades centradas no aluno visando possibilitar tanto o "aprendizado dos conceitos, termos e noções científicas quanto" o "aprendizado de ações, atitudes e valores próprios da cultura científica" (CARVALHO, 2013, p.13). Em uma atividade experimental investigativa, a ação do estudante não deve limitar-se puramente ao trabalho de manipulação de objetos, ou apenas da observação de fenômenos. Essa atividade deve conter características próprias "de um trabalho científico: em que o aluno deve refletir, discutir, explicar e relatar o que dará ao seu trabalho as características de uma investigação científica" (AZEVEDO, 2013, p. 21).

Desse modo, a seguir são apresentadas três alternativas de simulações virtuais que podem ser utilizadas para o ensino da Teoria Eletrofraca, ou, separadamente, para o ensino dos tópicos de: paridade nas interações fracas, correntes neutras, bósons da interação fraca e aceleradores de partículas. Serão feitas apresentações de aspectos técnicos presentes em todas as simulações e em seguida será feita uma descrição de cada uma das simulações e sugestões ${ }^{3}$ para as explorações das simulações.

\section{Apresentação das simulações}

Todas as simulações foram programadas para exibição em três idiomas (português, inglês e espanhol), assim os alunos e usuários podem optar pelo idioma de sua preferência. Desse modo, a primeira tela que aparece ao usuário é a de escolha dos idiomas.

As simulações são exploradas em passos, de modo que o usuário precisa completar todas as atividades do passo presente para seguir ao próximo, mas pode retornar e realizar passos anteriores quantas vezes achar necessário para testar suas hipóteses e tirar dúvidas. Desse modo, garante-se que o usuário adquira os conhecimentos prévios necessários antes que ele prossiga na realização do experimento virtual. Nas três simulações, esses passos estão distribuídos de forma semelhante. Primeiro o usuário escolhe o idioma que deseja utilizar

\footnotetext{
${ }^{3}$ As sugestões aqui apresentadas são advindas de uma Abordagem Didática preparada para apresentação do processo de desenvolvimento da Teoria Eletrofraca e está detalhada em Costa e Batista (2020).
} 
para, em seguida, ir ao primeiro passo da simulação, no qual os usuários montam o experimento, ou entendem como ele é formado. No próximo (ou próximos) passo(s), eles recebem a tarefa de realizar alguma atividade relacionada à execução do experimento. Depois, analisam resultados dos passos anteriores ou dados históricos dos experimentos originais e, por fim, no último passo, são apresentadas informações históricas a respeito do experimento simulado. Ao terminar e exploração, é exibida uma mensagem que indica que o usuário terminou a sua tarefa e apresenta os próximos desafios. Na Fig. 01, são apresentadas essas etapas.

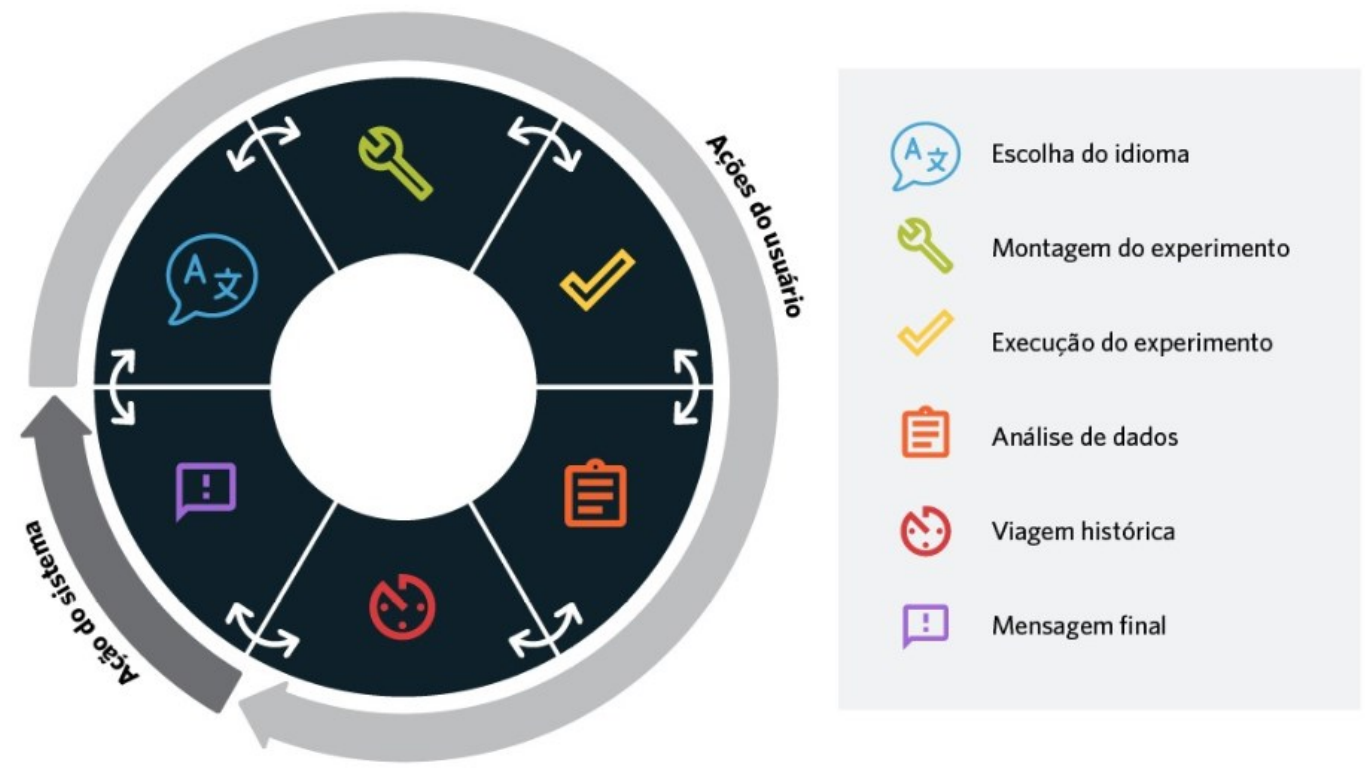

Fig. 01 - Fluxograma da exploração das simulações. Fonte: Autores.

Após selecionar o idioma, o usuário é apresentado à tela geral dos experimentos. Todos eles foram simulados seguindo um padrão. Isso facilita o trabalho do programador e a familiarização do usuário com a interface, pois ela segue o mesmo padrão de design nas três simulações propostas. Na Fig. 02 estão duas telas que apresentam a interface geral das três simulações e que também fazem parte do ícone ajuda "?", localizado no canto superior direito, que o usuário pode consultar durante a exploração da simulação, caso necessite.

Os usuários são guiados por mensagens que aparecem na parte superior, logo abaixo dos passos dos experimentos. Essas mensagens orientam a exploração e advertem em casos de erro. As mensagens de advertência indicam o erro e o motivo, assim os usuários podem aprender com seus erros e corrigi-los em próximas tentativas. Os usuários podem navegar por essas mensagens utilizando as setas expostas sobre elas e também podem excluir uma a uma, utilizando a lixeira, ou todas de uma vez só, utilizando o botão limpar mensagens. Para evitar confusões de informações, as mensagens são excluídas automaticamente quando o usuário vai para o próximo passo do experimento. 


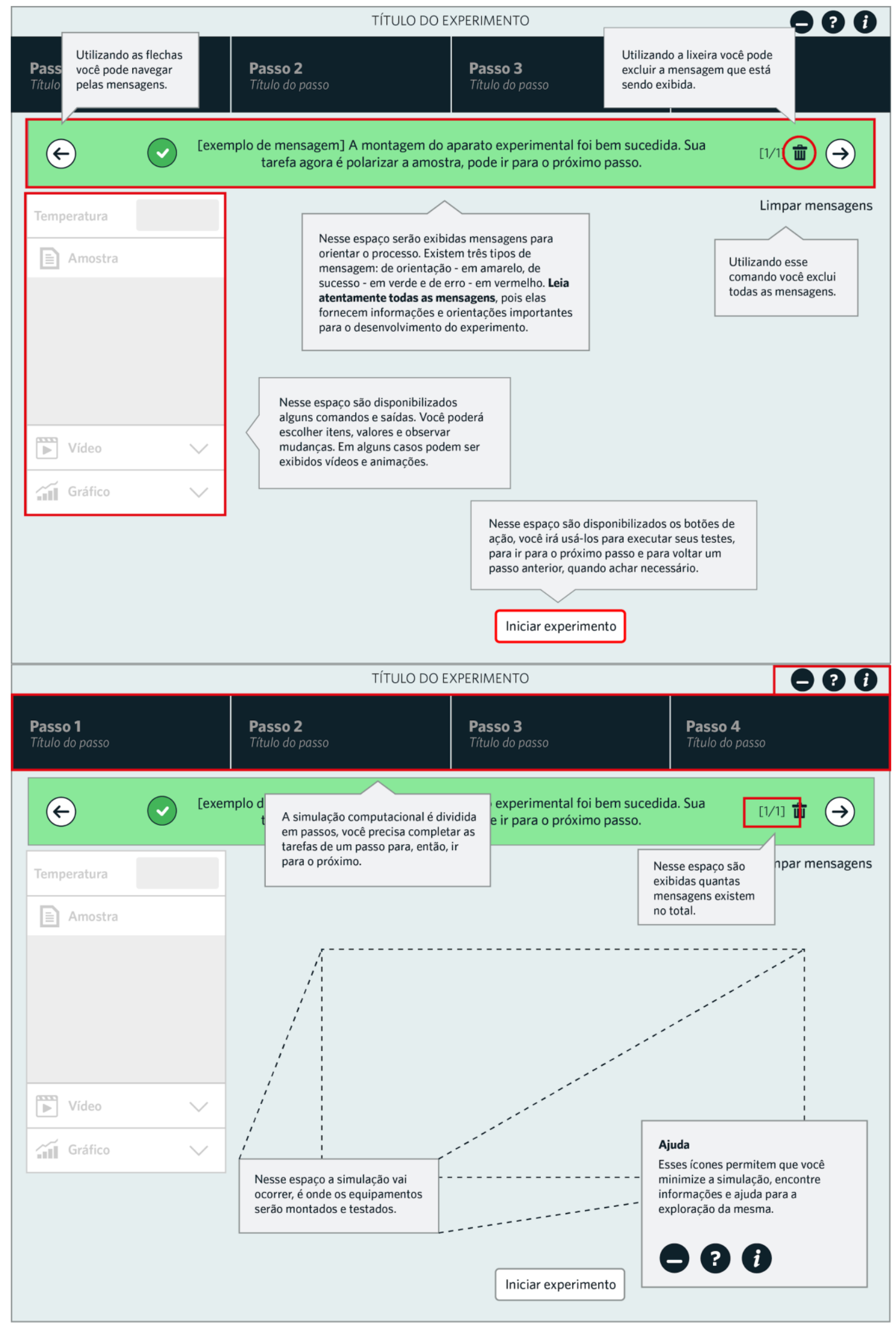

Fig. 02 - Representação da interface geral das simulações. Fonte: Autores. 
No painel de controle da esquerda o usuário poderá fazer escolhas e observar algumas saídas. Na parte inferior estão os botões de ação, com os quais os usuários podem fazer testes e navegar entre os passos e entre ações dentro dos próprios passos. Para sanar qualquer dúvida que os usuários tenham em relação à interface das simulações, eles podem acessar as informações, aqui apresentadas no ícone $i$, no canto superior direito.

Uma aula utilizando simulações virtuais pode apresentar os mesmos resultados de uma abordagem tradicional se o modo como a exploração ocorre não for orientado por uma perspectiva investigativa. Desse modo, tratando-se de uma simulação virtual de experimentos, sugere-se que as atividades que envolvam as mesmas sejam de caráter investigativo.

Assim, é relevante levar em consideração os conhecimentos prévios dos estudantes e permitir que os materiais complementares ajam como organizadores prévios, fontes de informação para a exploração das simulações, e apresentem o/os problema(s) que os usuários devem resolver por meio das simulações. Desse modo, se o objetivo é trabalhar com apenas uma das simulações aqui apresentadas, é necessário que ocorra uma introdução ao problema que a simulação pode responder e que os conhecimentos prévios para a exploração da simulação sejam fornecidos. Se o objetivo é trabalhar com as três simulações para abordar o processo de elaboração da Teoria Eletrofraca, os mesmos requisitos são necessários.

Além disso, há a necessidade de uma síntese das atividades, que pode ser um relatório escrito ou um $\mathrm{V}$ de Gowin. Essa síntese vai permitir que o professor mapeie o entendimento dos alunos em relação às atividades. Ainda, após a síntese individual produzida pelos alunos, o professor pode promover uma consolidação dos conteúdos para discutir os resultados do experimento e implicações desses, com o objetivo de corrigir eventuais imprecisões que os alunos possam apresentar em relação a isso, observar a manifestação de recursividade e, ainda, reforçar as conclusões obtidas por eles.

A seguir são apresentados os três experimentos que deram origem às simulações foco deste trabalho, suas respectivas simulações virtuais e sugestões para uma exploração investigativa.

\section{III.1 Experimento 1: Comportamento da Paridade nas Interações Fracas}

Ao longo do tempo, no decorrer do desenvolvimento científico, tem-se observado momentos em que ocorrem algumas explicações unificadoras de fenômenos que antes pareciam distintos, como é o caso da unificação da Gravitação Terrestre e da Gravitação Celeste, da Eletricidade e do Magnetismo, do Eletromagnetismo e da Óptica, da Interação Eletromagnética e da Interação Fraca, entre outros (SALAM; DIRAC; HEISENBERG, 1991). Esses momentos possibilitaram avanços científicos e tecnológicos que estão presentes em nosso cotidiano.

A unificação das interações fracas e eletromagnéticas foi proposta devido à uma sequência de acontecimentos que acabaram levando cientistas a propor que essas duas interações eram casos específicos de uma única interação, a eletrofraca. Os primeiros passos 
em direção a essa unificação foram dados após os resultados de um experimento que estudava o comportamento da paridade nas interações fracas.

A teoria que descrevia as interações fracas, até meados de 1950, era a Teoria de Fermi, que explicava o decaimento beta, o comportamento dos mésotrons e o decaimento das partículas estranhas. Mas havia o problema no qual duas novas partículas $\theta$ (theta) e $\tau$ (tau), com massas e tempo de vida parecidos, eram tidas como produto do decaimento da partícula $\mathrm{K}$, hoje denominada Káon. No entanto, ao observar os valores de paridade para o decaimento de cada uma dessas partículas, os valores encontrados eram diferentes, o que, na época, não era permitido teoricamente.

Lee e Yang (1956) trabalharam no enigma " $\theta-\tau$ ": duas partículas, aparentemente iguais (mesma massa e mesmo tempo de vida), apresentavam decaimentos diferentes (o que não era permitido pela conservação da paridade). Em estudos a respeito da questão da conservação de paridade nas interações fracas, Lee e Yang chegaram à conclusão de que não existia evidência experimental para corroborar ou refutar a conservação da paridade nessas interações. Sendo assim, propuseram alguns experimentos que poderiam resolver esse impasse (LEE; YANG, 1956).

Chien-Shiung $\mathrm{Wu}$, que era especialista em decaimento beta, após uma conversa com Lee, na qual discutiram avanços nos experimentos relacionados ao decaimento beta e à conservação da paridade, começou a investigar a questão da paridade no decaimento beta. Nessa conversa, Wu perguntou a respeito dos métodos indicados para um possível teste. Lee comentou que havia sugestões de utilização de núcleos polarizados produzidos em reações nucleares, ou a utilização de um feixe de nêutrons lentos polarizados por meio de um reator. $\mathrm{Wu}$ analisou as ideias e sugeriu que seria mais eficiente utilizar núcleos de cobalto 60 polarizados pelo método de desmagnetização adiabática (HAMMOND, 2010).

O processo desse decaimento é o seguinte: ${ }_{27}^{60} \mathrm{Co} \rightarrow{ }_{28}^{60} \mathrm{Ni}+e^{-}+\bar{v}_{e}+2 \gamma$, no qual um dos nêutrons do núcleo do cobalto decai para um próton por emissão de um elétron $\left(e^{-}\right.$, partícula beta) e seu antineutrino $\left(\bar{v}_{e}\right)$, transformando-se em um núcleo de Níquel $\left({ }_{28}^{60} \mathrm{Ni}\right)$ que, por sua vez, volta para seu estado fundamental com a emissão de dois raios gama ( $2 \gamma$, fótons).

A ideia do experimento foi alinhar os spins nucleares em duas direções, para cima e para baixo. Uma delas corresponderia à imagem real, e a outra corresponderia à imagem espelhada. Se a paridade fosse conservada, então, as partículas emitidas deveriam surgir em iguais quantidades tanto para cima quanto para baixo. Se não, no espelho, onde a rotação é invertida, o que se observaria seria diferente. E, se isso acontecesse, a paridade não seria conservada. Na Fig. 03, representa-se um núcleo e partículas beta (elétrons) sendo emitidas. A sequência de Fig. 3A, 3B e 3C representa um caso de transformação de paridade e o que se espera, caso a paridade se conserve.

$\mathrm{Na}$ Fig. 3A, um núcleo gira no sentido anti-horário e tem o sentido de seu eixo de rotação para cima. Agora, imagine essa imagem espelhada. Com isso, o sentido do giro 
inverte e, consequentemente, o sentido do eixo de rotação também é alterado (Fig. 3B). O próximo passo é girar a imagem espelhada em $180^{\circ}$, assim o sentido do giro e do eixo de rotação volta ao quadro original (Fig. 3C). Isso completa uma transformação de paridade, como descrito em Forman (1982).

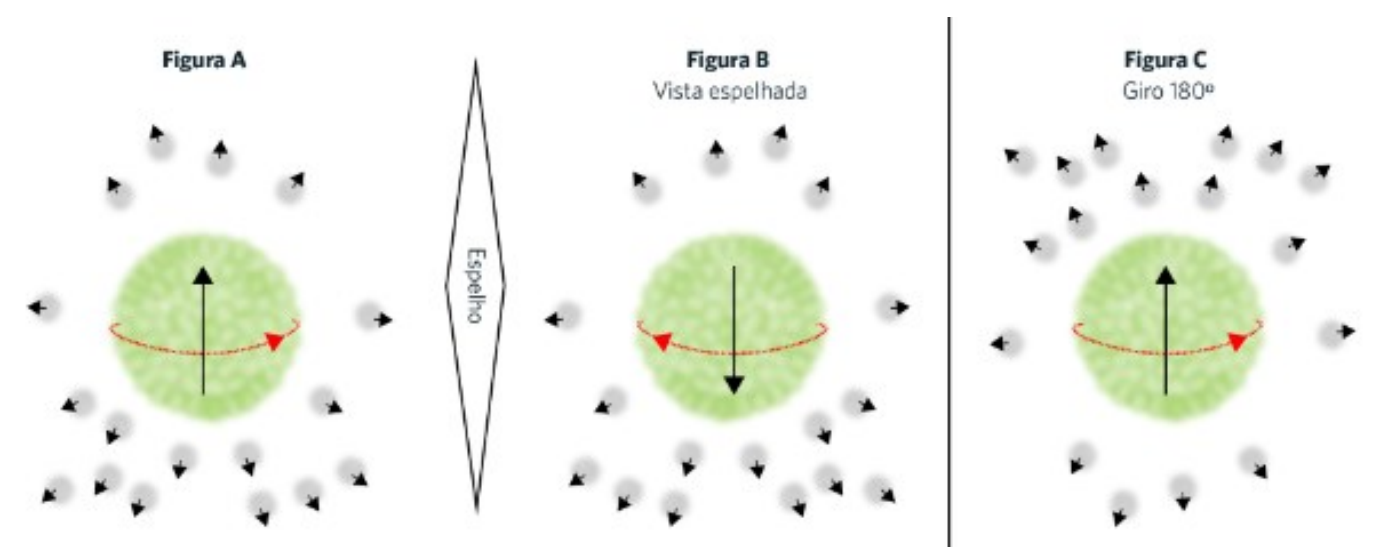

Fig. 03 - Representação de uma transformação de paridade. Fonte: Costa (2019).

Ao analisar as imagens $\mathrm{A}$ e $\mathrm{C}$, pode-se interpretar que o esperado é que o número de emissão de partículas, durante o decaimento, seja igual, tanto na direção do eixo de rotação quanto na direção oposta. Isso representaria a conservação da paridade, uma vez que, quando o número de emissões é uniforme em todas as direções, os decaimentos com alinhamento para cima e para baixo seriam indistinguíveis.

De acordo com Wu (1996), a conservação de paridade afirma que nenhuma nova lei física deve resultar da construção de um sistema que seja diferente do original por ser uma imagem espelhada. Ou seja, não existe uma distinção absoluta entre um objeto real e sua imagem espelhada: os dois sistemas deveriam obedecer às mesmas leis físicas. Em outras palavras, duas partículas radioativas semelhantes, que giram em sentidos opostos em torno do mesmo eixo, devem emitir a mesma intensidade de radioatividade em qualquer direção dada. Foi isso que os cientistas procuraram estudar no experimento. Alinharam os átomos em duas direções, para cima e para baixo, e observaram o número de emissões nos dois casos.

É esse o problema que os alunos deverão solucionar por meio da exploração da simulação virtual desse experimento: a paridade se conserva ou não, na interação fraca?

No entanto, o aluno não pode ser posto frente a essa simulação sem a devida preparação inicial. Aconselha-se uma introdução ao problema para que os alunos tenham os conhecimentos prévios necessários para dar início à exploração da simulação. Dentre esses conhecimentos prévios, podem-se citar: definição de interações fracas e eletromagnéticas, decaimento beta, o problema " $\theta-\tau$ ”, polarização, paridade, entre outros que se julgar necessário. 
Desde a ideia de como realizar o teste experimental e a consolidação do mesmo, muitos problemas precisaram ser resolvidos pelos cientistas e a sugestão é que esses problemas sejam apresentados aos alunos, para que eles possam pensar em possíveis soluções e testar suas hipóteses na exploração da simulação. Desse modo, a exploração das simulações vai apresentar um caráter investigativo.

Uma das alternativas é apresentar os problemas por meio de uma exposição oral e complementar com um texto que pode servir de guia para os alunos iniciarem a simulação do experimento. A ideia é que os alunos reúnam as informações do texto e da exposição oral com as informações da simulação e assim consigam tomar suas decisões.

Por exemplo, um dos desafios enfrentados para a realização do experimento real consistia no fato de que o processo precisava ser feito em um equipamento que permitisse isolamento térmico suficiente para realizar as medidas. Para resolver esse problema, foi utilizado um dispositivo que controlava e mantinha baixas temperaturas. Assim, colocando a amostra e o detector de partículas beta dentro desse recipiente, se conseguia garantir um isolamento térmico para efetuar as medidas. Essas informações podem ser dadas em um texto e/ou de forma oral, uma vez que na simulação há uma informação semelhante na descrição do Criostato, que é um dos itens disponíveis para a montagem do experimento. Dessa forma, os alunos poderiam reunir as informações e perceber que o criostato é um dos itens que precisam para realizar a montagem do experimento.

Ao começar a exploração dessa simulação, os alunos recebem uma mensagem, conferindo-lhes a tarefa de montar o aparato experimental e, para isso, a simulação tem à disposição uma lista de materiais que podem, ou não, ser úteis na realização do experimento. Os alunos podem fazer suas escolhas com base nas informações prévias e testar suas hipóteses. Caso eles errem a escolha de algum item, a simulação exibe uma mensagem alertando o erro e do motivo do erro. Assim, eles entendem o motivo de terem errado e podem aprender com isso. Esse corresponde ao primeiro passo da simulação, que está representado na Fig. 04.

No segundo passo, os usuários recebem a tarefa de polarizar a amostra. Para isso, a simulação vai dando dicas de como isso pode ser alcançado e deixa o usuário realizar as ações para tornar isso possível e observar o que acontece com a amostra em termos de alinhamento e temperatura.

No terceiro passo, é simulado o processo de alinhamento da amostra em duas direções e a detecção das partículas emitidas pelo decaimento da amostra. Neste momento, os usuários entendem como são feitos esses processos, realizam as ações para tornar isso possível e visualizam a simulação de efeitos do alinhamento e emissão de elétrons.

No quarto passo, os usuários precisam analisar os resultados obtidos da emissão das partículas para os dois alinhamentos diferentes. Eles fazem isso por meio de questões de múltipla escolha que permitem que eles expressem seus entendimentos a respeito dos resultados. Ao escolher uma alternativa, a simulação exibe uma mensagem de confirmação da 
resposta, assim os usuários são levados a refletir a respeito da alternativa que estão escolhendo. Se os usuários erram as respostas, a simulação exibe uma mensagem explicando o motivo do erro e permitindo que eles reflitam melhor a respeito das questões.

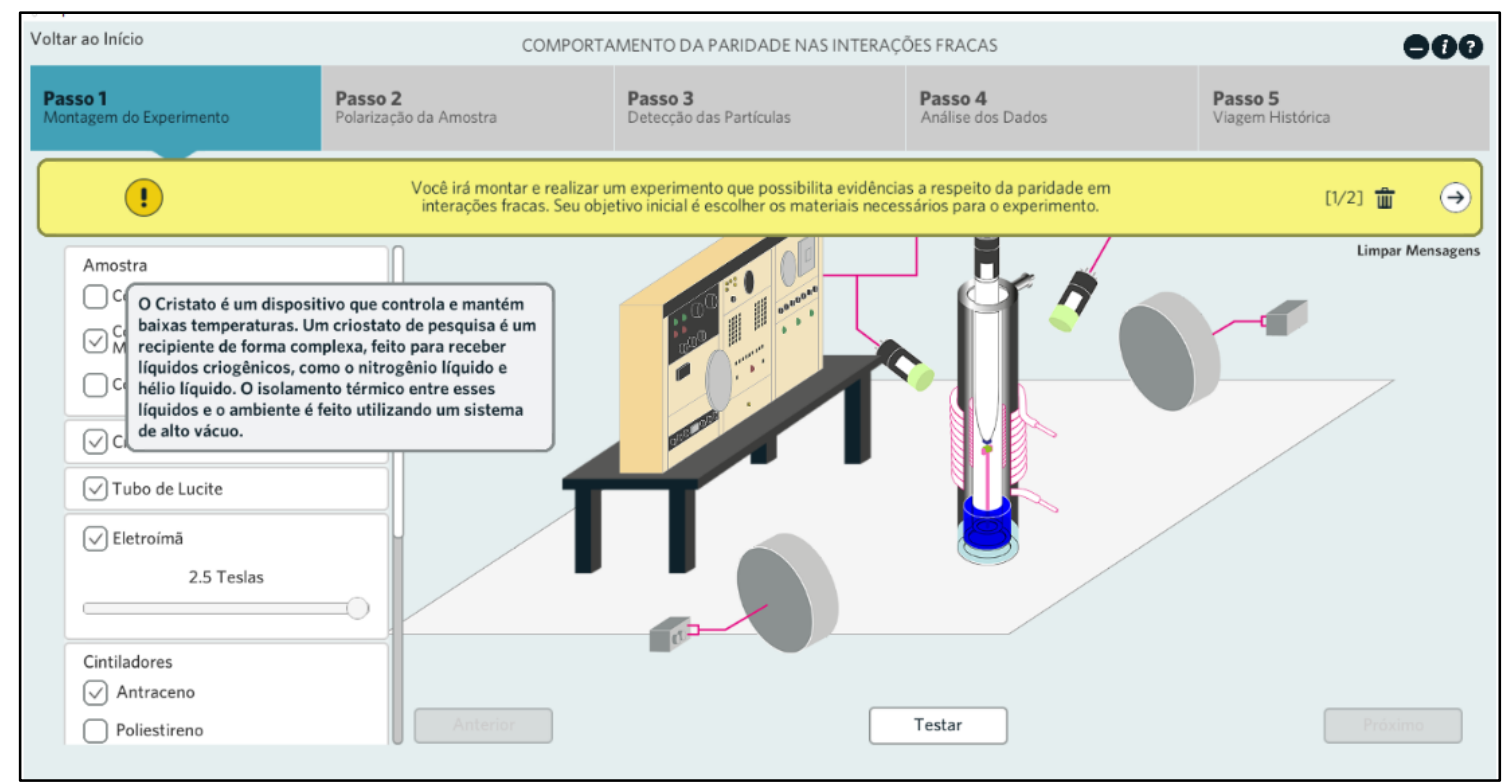

Fig. 04 - representação do primeiro passo da simulação computacional.

Fonte: Autores.

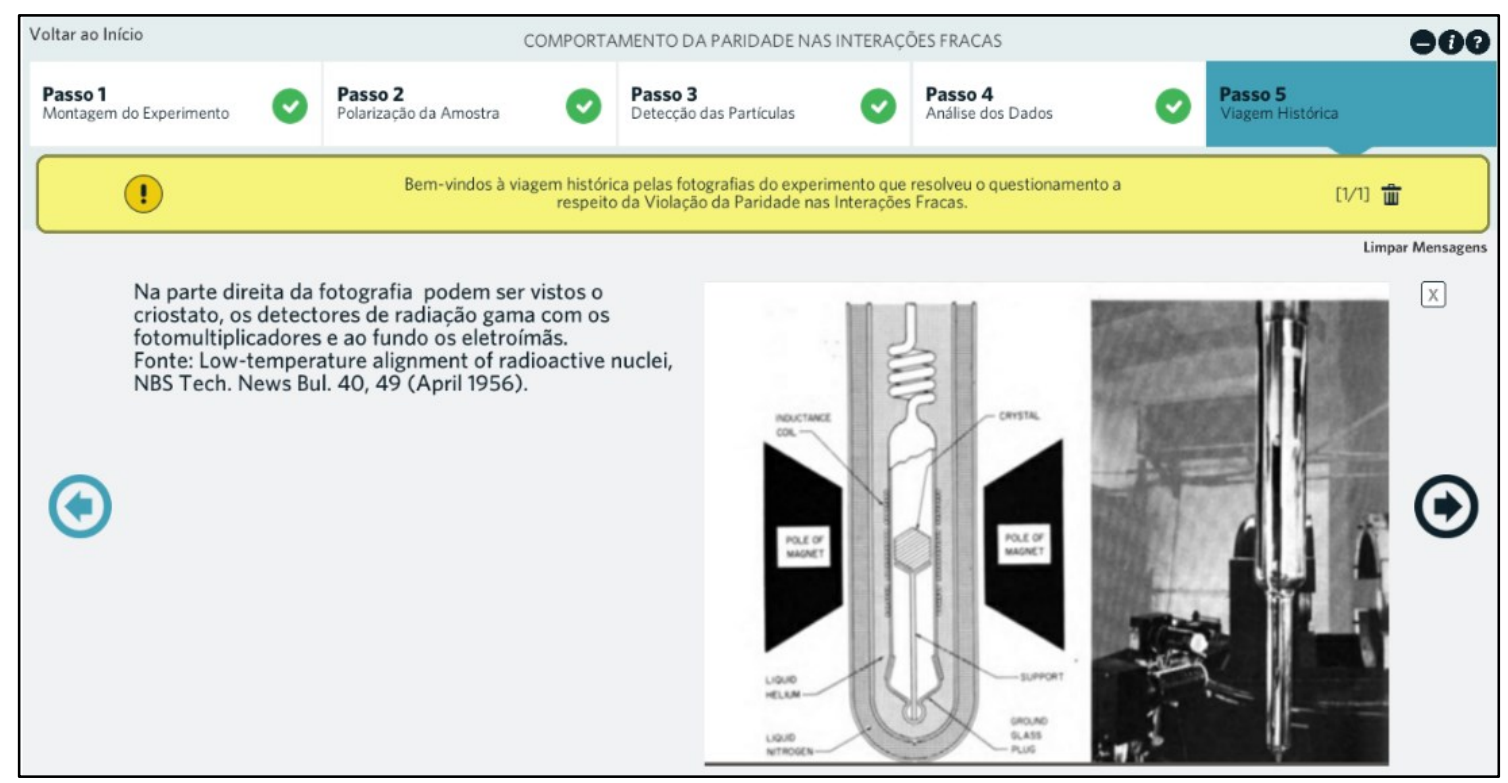

Fig. 05 - Representação do passo 5. Fonte: Autores 
Por fim, no passo 5, os usuários podem consultar registros históricos a respeito do experimento simulado, como fotos dos aparatos experimentais e da equipe realizando o experimento, bem como um print do artigo original com os nomes dos cientistas responsáveis pelo experimento. A representação desse passo está na Fig. 05, em que os alunos podem navegar pelos registros utilizando as setas.

Ao término da exploração da simulação, é necessário que o aluno expresse seu entendimento a respeito do processo, dos resultados e das implicações desses para a teoria que descrevia as interações fracas. Com isso, os alunos devem entender que o resultado do experimento não é explicado pela teoria vigente da época e que reformulações precisam ser feitas para que a teoria possa explicar esse fenômeno recém evidenciado. A mensagem final exibida aos alunos inicia essa reflexão, como representado na Fig. 06.

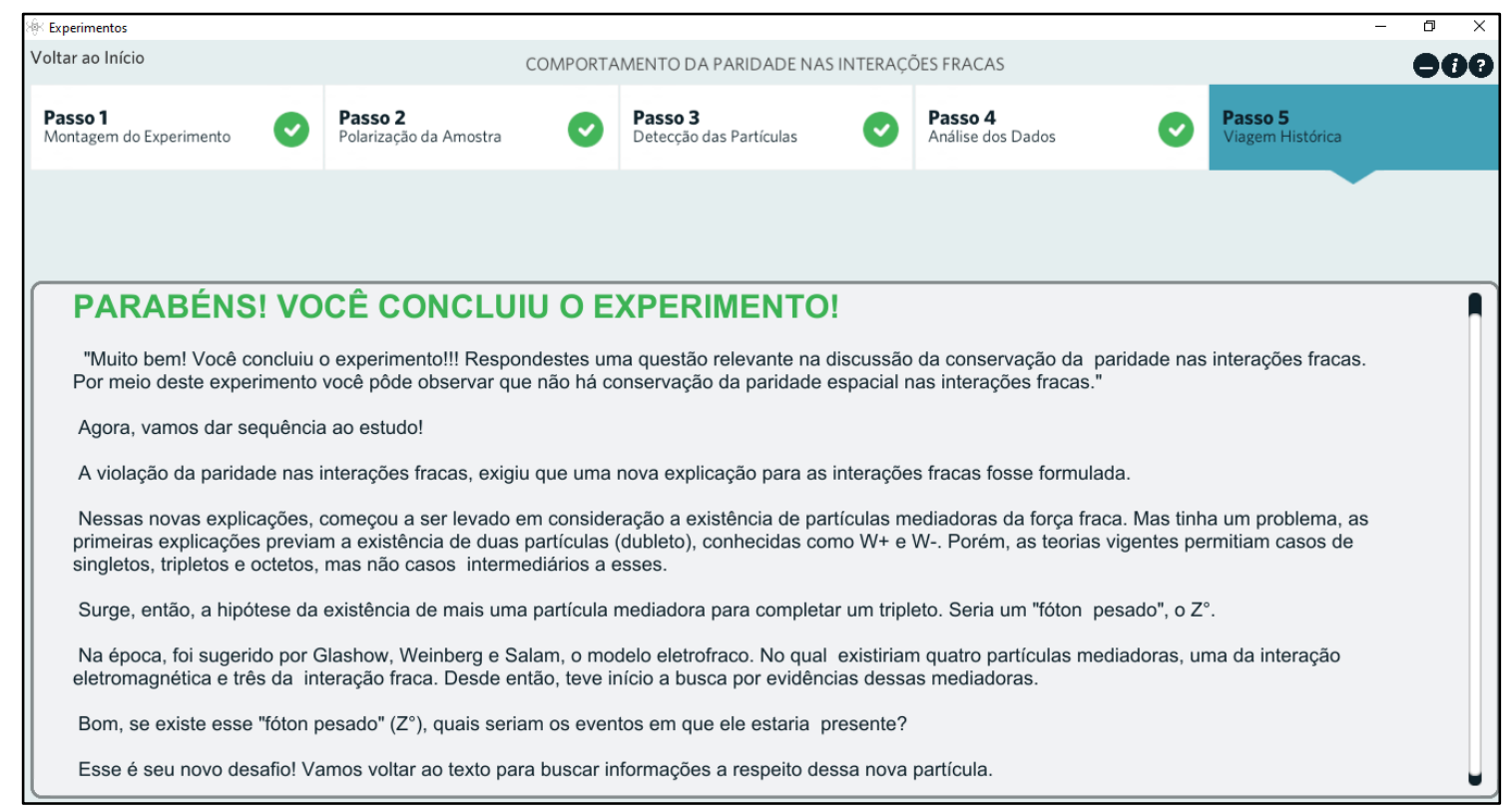

Fig. 06 - Representação da mensagem final ao término da simulação.

Fonte: Autores.

\section{III.2 Experimento 2: Detecção das Correntes Neutras}

Foram as reformulações da teoria de Fermi que passaram a se chamar Teoria V - A, que levaram às primeiras hipóteses de bósons mediadores para a interação fraca e a possibilidade de relação entre essa interação e a eletromagnética.

No início, pensou-se em duas partículas de mesma massa e cargas opostas. Porém, esse era outro problema. Pois, pelas previsões teóricas, não poderia existir um dobleto de mediadoras - poderia existir um singleto, tripleto, octeto, mas não casos intermediários a esses.

Após contribuições de vários cientistas, inclusive brasileiros, como José Leite Lopes, uma proposta teórica foi elaborada para explicar a interação fraca e sua relação com a interação eletromagnética. A Teoria Eletrofraca foi formalizada, independentemente, por 
Glashow, Weinberg e Salam, na qual existem quatro partículas mediadoras, uma da interação eletromagnética (fóton) e três da interação fraca $\left(\mathrm{W}^{+}, \mathrm{W}^{-}\right.$, e $\left.\mathrm{Z}^{0}\right)$. Desde então, teve início a busca por evidências dessas mediadoras (GLASHOW, 1980; WEINBERG, 1980; SALAM, 1980).

A Teoria Eletrofraca previa a existência de um bóson neutro, $Z^{0}$, que seria responsável pelo surgimento das correntes neutras, até então desconhecidas teoricamente e nunca observadas experimentalmente. Esse foi o primeiro desafio dos cientistas, tanto teóricos como experimentais: prever em que situações essas correntes poderiam ser observadas para, então, ter evidências de que a Teoria Eletrofraca estava coerente.

Os processos de decaimento conhecidos até então provocavam mudança de carga elétrica, por isso dizia-se que o processo era causado por correntes carregadas. Porém, a hipótese de um bóson neutro implicava a existência de correntes neutras, ou seja, processos em que não havia mudança de carga elétrica, apenas transferência de momento.

A teoria de Glashow, Salam e Weinberg permitiu que a massa das partículas W e Z fossem previstas com maior precisão, o que facilitou a caracterização das correntes neutras provocadas por $Z^{0}$, e tornava a existência das correntes neutras a primeira evidência experimental do modelo padrão eletrofraco (WEINBERG, 1980; FORTES; TIJERO; PLEITEZ, 2007).

Uma das maneiras de investigar a interação fraca era disparar feixes de neutrinos em um alvo fixo e observar o que acontece. Como os neutrinos experimentam somente a ação da interação fraca, essas experiências prometiam revelar propriedades dessa interação de maneira muito mais clara do que as experiências utilizando decaimentos, uma vez que essas também sofriam efeitos das interações fortes e eletromagnéticas. Entretanto, também era claro que os experimentos exigiriam feixes intensos de neutrinos e detectores muito grandes para que pudesse ser observado qualquer efeito, dado que a interação do neutrino com a matéria era de difícil detecção (PICKERING, 1984).

Apesar dessa evidente dificuldade, os experimentos com neutrinos começaram no início da década de 1960, nos dois principais laboratórios de Física de Partículas da época: o Laboratório Nacional de Brookhaven (BNL), nos Estados Unidos, e o CERN, localizado na fronteira entre França e Suíça. Enquanto os primeiros experimentos com neutrinos aconteciam nesse período, um grupo de físicos franceses, liderado por Lagarrigue, estava construindo uma grande câmara de bolhas, chamada Gargamelle. Essa câmara consistia em um tanque cheio de um líquido superaquecido, mantido sob pressão para evitar que fervesse. Quando um feixe de neutrinos, por exemplo, é disparado no tanque, pequenas bolhas começam a se formar ao longo de trilhas de partículas carregadas, produzidas na interação entre o neutrino e o núcleo do líquido superaquecido. Essas trilhas são fotografadas e podem ser analisadas posteriormente. $\mathrm{O}$ motivo para a construção de uma câmara grande era aumentar a taxa de interação do neutrino com o líquido que preencheria seu interior. Além disso, a Gargamelle 
foi projetada para ser preenchida com um líquido muito denso, o fréon, o que aumentaria ainda mais a taxa de interação (PICKERING, 1984).

Foi por meio de experimentos na Câmara de Gargamelle que se evidenciou a presença das correntes neutras (provocadas pela troca de $Z^{0}$ ) e das correntes carregadas (provocadas pela troca de $\mathrm{W}^{+}$e $\mathrm{W}^{-}$). É esse o segundo experimento simulado que os alunos devem explorar para entender como esse processo ocorreu e quais os resultados obtidos. Desse modo, um dos problemas que podem ser apresentados aos alunos é o próprio questionamento da existência, ou não, das correntes neutras.

Novamente, não se aconselha que o aluno explore a simulação sem os devidos conhecimentos prévios. Dentre esses conhecimentos, podem-se citar: a teoria eletrofraca, correntes neutras e carregadas, interações com neutrinos, técnicas de detecção de correntes neutras e carregadas, etc. Assim como sugerido para a simulação anterior, a ideia é que a exploração da simulação apresente um caráter investigativo, então, sugere-se que o problema da detecção das correntes neutras seja apresentado aos alunos como um desafio, para que explorem a simulação com o objetivo de entender e responder se as correntes neutras existem ou não. Como material complementar, pode ser utilizado um texto e/ou uma exposição oral, com as mesmas características do material complementar da simulação apresentada anteriormente, que reúnam as informações para realizar as tarefas propostas. Sugerimos, também, uma contextualização teórico-conceitual prévia com enfoque histórico baseado nos problemas físicos prévios, suas resoluções e seus aspectos conceituais ainda em aberto.

O primeiro passo dessa simulação é a montagem do aparato experimental. Para isso, a simulação apresenta uma lista de materiais que podem ou não ser úteis na realização do experimento. Os alunos vão fazer suas escolhas com base nas informações obtidas na simulação e no material complementar. Sempre que erram a montagem, a simulação exibe uma mensagem de advertência e explica o motivo do erro para que possam corrigi-lo, como pode ser notado na Fig. 06.

$\mathrm{Na}$ segunda etapa da simulação, após a montagem adequada do experimento, os alunos são guiados para entender o funcionamento da câmara de bolhas, desde a emissão dos neutrinos e antineutrinos até seu processo de detecção, passando pela pressurização e despressurização da câmara. Uma representação desse passo é apresentada na Fig. 07.

No terceiro passo, são expostas algumas representações fictícias de detecção e informações a respeito das partículas detectadas em cada uma delas, representadas na Fig. 08. Com isso, os alunos são levados a interpretar essas detecções fictícias e tentar identificar quais delas podem ser evidências da presença de correntes neutras. Se os alunos erram a alternativa, a simulação exibe uma mensagem de advertência e volta às alternativas para que os alunos escolham outra. 


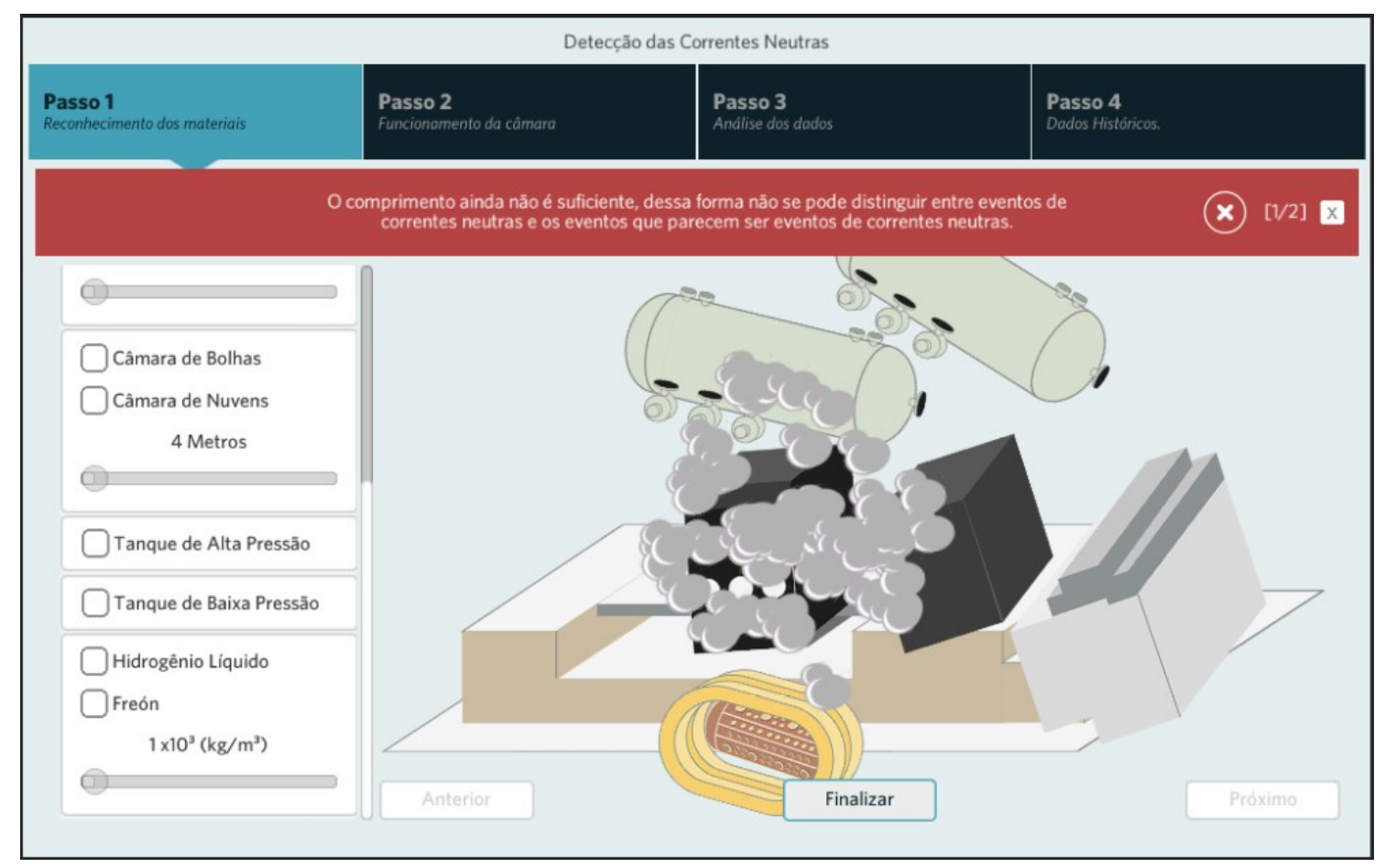

Fig. 06 - Representação das mensagens e animações de erro. Fonte: Costa (2019).

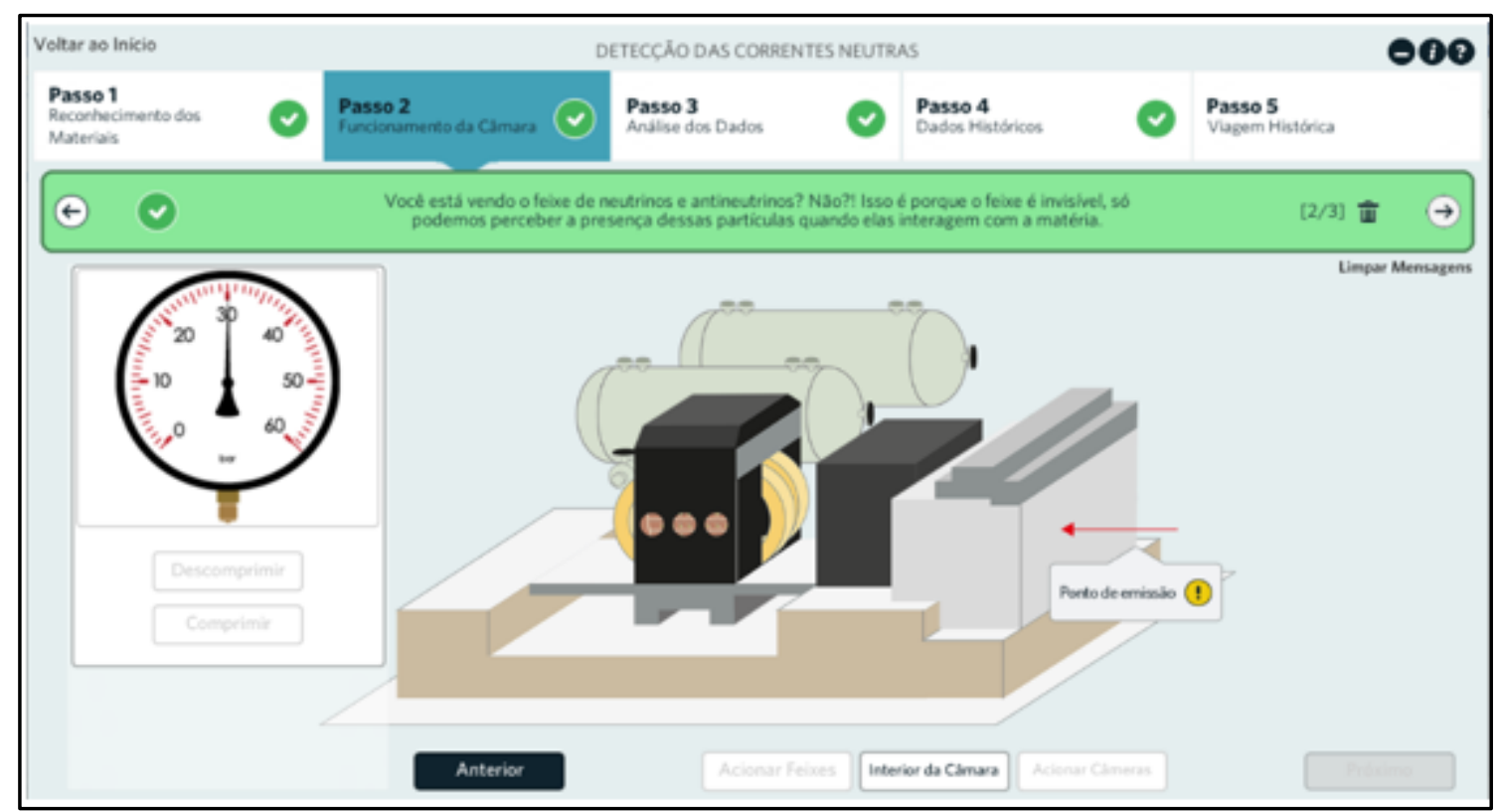

Fig. 07 - Representação do passo 02 da segunda simulação computacional. Fonte: Autores. 


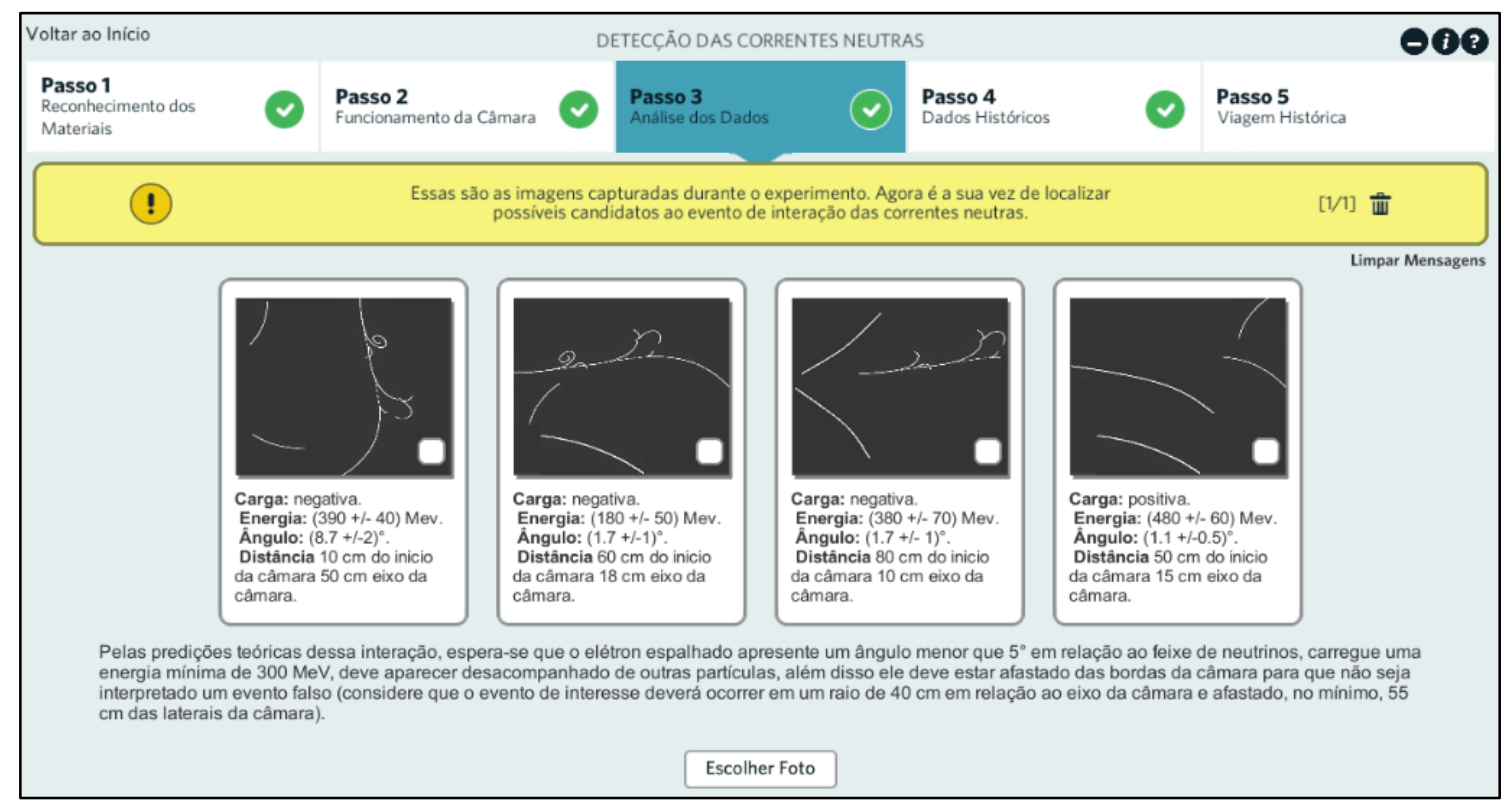

Fig. 08 - Representação do passo 03 da segunda simulação computacional.

Fonte: Autores.

No quarto passo, os usuários podem consultar dados históricos da detecção real da evidência das interações fracas. É exibida a imagem original da detecção e a explicação da mesma.

No quinto passo, assim como na primeira simulação, são exibidos registros históricos do experimento, fotografias de fases do processo experimental e um print do artigo em que foram publicados os resultados do experimento original. Ao comparar o número de cientistas envolvidos no primeiro experimento simulado e nesse segundo, os alunos podem observar a presença significativa da colaboração científica.

Ao final da exploração dessa simulação, é necessário que os alunos expressem uma síntese do entendimento dos mesmos a respeito do processo experimental e dos resultados obtidos. Assim, ficará claro que esse experimento foi a primeira evidência experimental da Teoria Eletrofraca e que, assim como todo processo de solução para um problema, surgem novos desafios, como por exemplo, a detecção dos bósons da interação fraca.

Porém, antes de seguir para a explicação do terceiro experimento simulado, convém registrar que a literatura indica 4 experimentos como relevantes no processo de consolidação da Teoria Eletrofraca: os três aqui apresentados e um quarto experimento que ocorreu entre o experimento da câmara de Gargamelle e o experimento com detectores UA1 e UA2. Esse experimento não foi simulado computacionalmente por não terem sido encontradas informações históricas e técnicas suficientes para isso. Mais detalhes desse experimento podem ser consultados em Costa (2019). 


\section{III.3 Experimento 3: Detecção indireta dos bósons da interação fraca ( $\mathbf{W}^{+}, \mathbf{W}^{-}$e $\left.Z^{0}\right)$}

O passo seguinte foi a busca pela detecção dos três bósons mediadores da interação fraca. As primeiras etapas foram previsões teóricas de massa, tempo de decaimento e possíveis produtos desse decaimento, uma vez que não é possível fazer a detecção direta desses bósons devido ao fato de decaírem rapidamente.

Quanto ao produto do decaimento, como $Z^{0}$ é neutro, espera-se que ele decaia em um par lépton-antilépton (ex.: elétron e pósitron, múon e antimúon), pela lei de conservação de cargas e de números quânticos. Já de $\mathrm{W}^{+}$e $\mathrm{W}^{-}$, espera-se que decaiam em um lépton ou um antilépton e seus neutrinos ou antineutrinos (ex.: elétron e antineutrino do elétron, pósitron e neutrino do elétron).

Para procurar esses eventos, foram utilizadas colisões frontais de feixes de prótons e antiprótons a $540 \mathrm{GeV}$. Esses feixes foram gerados no CERN (Conseil Européen pour la Recherche Nuclèaire) como produtos finais de uma sequência de eventos em vários anéis aceleradores interligados.

Primeiro, os feixes de prótons eram acelerados em um acelerador linear (LINAC) até uma energia de $50 \mathrm{MeV}$. Depois, eram direcionados para um Síncrotron Impulsionador, formado por um conjunto de quatro anéis (BOOSTER), para serem acelerados até adquirirem uma energia de $800 \mathrm{MeV}$. Em seguida, eram direcionados para o acelerador Próton Síncrotron (PS), no qual seriam acelerados até obterem uma energia de $26 \mathrm{GeV}$. E então, dirigidos para um alvo de metal, o que produziria antiprótons com uma energia de 3,5 GeV (WATKINS, 1986; CLINE et al., 1982).

Esses antiprótons eram recolhidos para um acumulador de antipróton (AA), onde eram resfriados por um processo conhecido como resfriamento estocástico. Após obter um feixe suficientemente denso, eles eram enviados para o acelerador PS e acelerados a uma energia de $26 \mathrm{GeV}$. Em seguida, eram injetados no acelerador Super Próton Síncrotron (SPS), onde os prótons já estavam circulando com a mesma energia e em sentido oposto. Então, os dois feixes eram acelerados a $270 \mathrm{GeV}$ e levados a colidirem. A energia liberada na colisão era suficiente para gerar as mediadoras $\mathrm{W}^{-}, \mathrm{W}^{+}$e $\mathrm{Z}^{0}$, e os produtos de seus decaimentos poderiam ser registrados nos detectores UA1 e UA2, colocados em volta do ponto de colisão (WATKINS, 1986; CLINE et al., 1982).

O detector UA1 era formado por uma série de detectores que possibilitavam identificar características de diferentes partículas que eram geradas no momento da colisão. Ele era formado por um detector central, calorímetros eletromagnéticos e hadrônicos, bobina de alumínio e um detector de múons. Foi esse experimento que possibilitou as primeiras evidências indiretas das partículas mediadoras da interação fraca $W^{-}, W^{+}$e $Z^{0}$ e é esse processo experimental que os alunos exploram nessa terceira simulação.

Nessa simulação, diferente das duas primeiras, a primeira etapa é mais informativa do que interativa. No primeiro passo, obtém-se conhecimento do funcionamento do sistema de aceleração e detecção dos bósons. Na tela, representada na Fig. 09, é exibido um esboço do 
sistema de aceleração, e o usuário deve navegar por todos os itens para poder seguir para a segunda etapa, na qual irá interagir com a simulação para gerenciar o processo de produção de antiprótons.

No segundo passo, o usuário precisa tomar decisões relacionadas ao direcionamento de feixes de prótons e antiprótons, bem como faixas de energia e tempo para serem aplicados aos diferentes processos. Ao final, deve ficar claro como ocorre o processo de produção de antiprótons, quais os aceleradores, quantidades de energia e tempo são necessários para obter feixes de prótons e antiprótons disponíveis para a colisão.

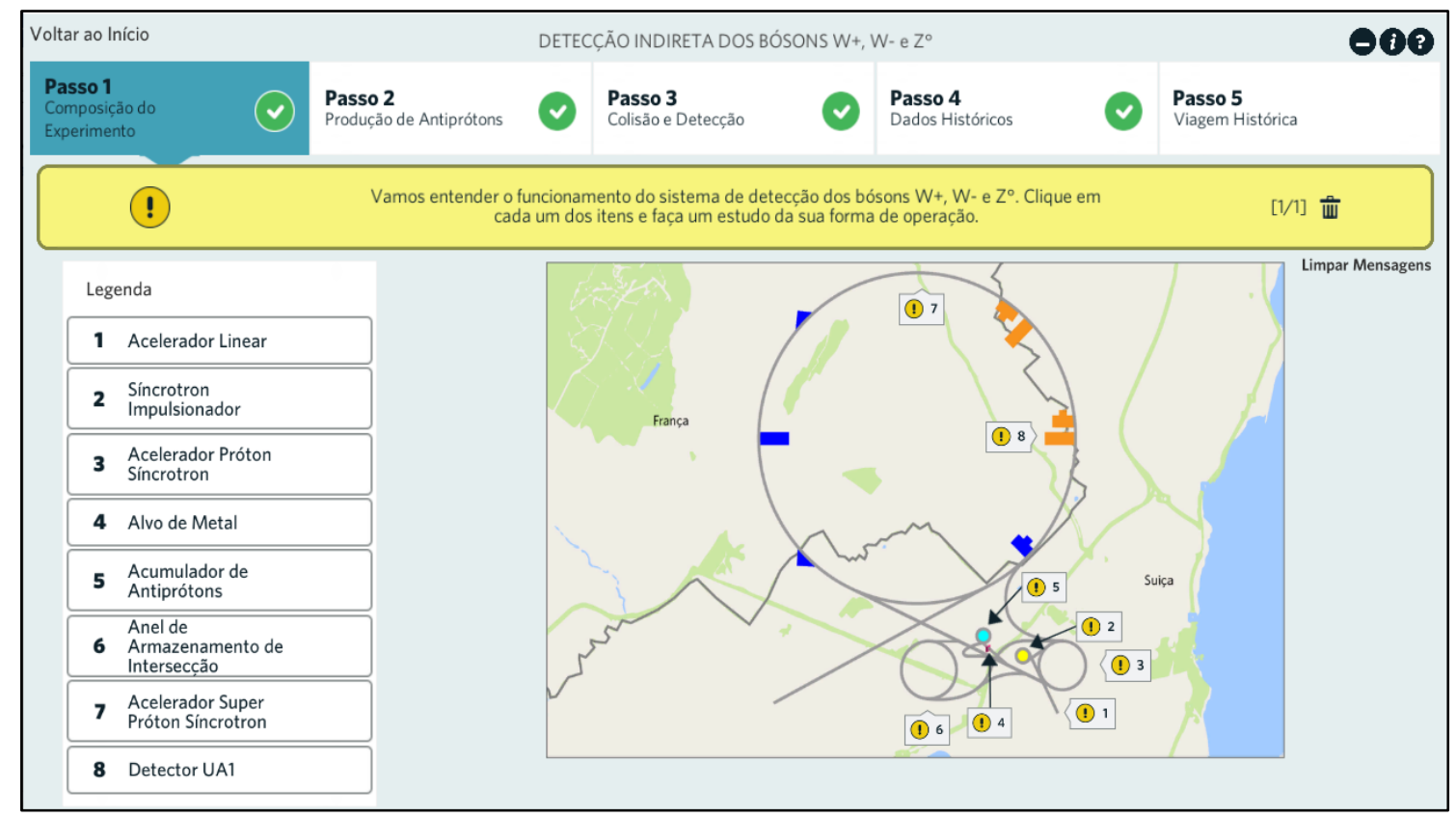

Fig. 09 - Representação do passo 01 da terceira simulação computacional.

Fonte: Costa (2019).

No passo 3, representado na Fig. 10, os alunos montam e entendem como funciona o detector UA1, testam a montagem, iniciam a colisão entre os feixes de prótons e antiprótons e compreendem como se dá esse processo.

No passo 4, são exibidos os dados históricos das detecções originais, além dos processos de decaimento e as imagens que representam a evidência desses decaimentos.

A última etapa, assim como nas outras simulações, é uma viagem histórica por fotografias que registram partes do experimento e também o print do artigo no qual foram publicados os resultados a respeito do experimento original.

Novamente, ao fim da exploração da simulação, é necessário que os alunos expressem o que entenderam do processo e dos resultados experimentais. Sugere-se que, após a síntese dos alunos, os professores também promovam uma discussão para deixar claras as 
implicações desse resultado experimental, atividade essa que pode ajudar os alunos a entender de forma coerente os resultados ou reforçar as conclusões já obtidas por eles.

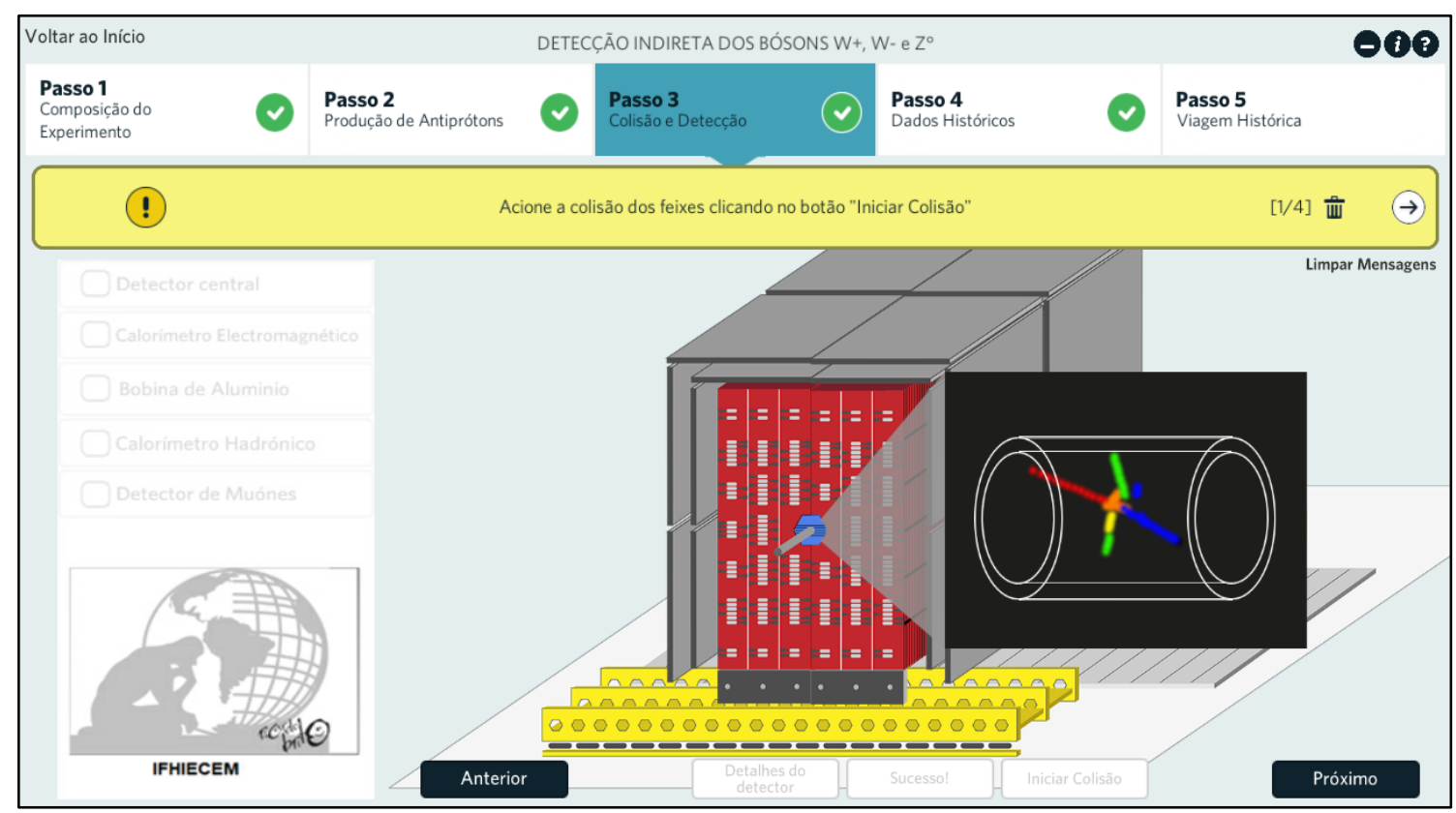

Fig. 10 - Representação do passo 03 da terceira simulação computacional.

Fonte: Autores.

\section{Unidade didática para exploração de simulações virtuais}

Diante do que já foi descrito para a exploração das simulações acima apresentadas, no Quadro 01 é sugerido um modelo de Unidade Didática (ZABALA, 1998) inspirada em atividades investigativas (AZEVEDO, 2013; CARVALHO, 2013) e na Teoria da Aprendizagem Significativa (AUSUBEL, 2003; GOWIN; ALVAREZ, 2005), que pode auxiliar professores na elaboração das atividades de ensino e facilitar o processo de aprendizagem de estudantes.

O ensino investigativo, base teórico-metodológica para atividades investigativas, é uma estratégia didática utilizada para elaborar sequências de atividades centradas no aluno visando possibilitar tanto o "aprendizado dos conceitos, termos e noções científicas quanto" o "aprendizado de ações, atitudes e valores próprios da cultura científica" (CARVALHO, 2013, p. 13). Ao pensar em uma atividade experimental investigativa, a ação do estudante não deve limitar-se puramente ao trabalho de manipulação de objetos, ou apenas de observação de fenômenos. Essa atividade deve conter características próprias "de um trabalho científico: em que o aluno deve refletir, discutir, explicar e relatar, o que dará ao seu trabalho as características de uma investigação científica" (AZEVEDO, 2013, p. 21). Desse modo, a exploração de simulações de experimentos históricos pode ser uma alternativa para promover 
atividades dessa natureza, na qual os estudantes, a partir de um problema, levantam suas hipóteses, testam e elaboram conclusões de acordo com as observações obtidas.

Quadro 01 - Sugestão de uma Unidade Didática para exploração das simulações.

\begin{tabular}{|c|c|c|}
\hline PASSOS & SEQUENCIA DE ATIVIDADES & \\
\hline 1 & Apresentação & \multirow{6}{*}{$\begin{array}{l}\text { Atividades relacionadas } \\
\text { à Teoria de Aprendizagem } \\
\text { Significativa }\end{array}$} \\
\hline 2 & Obtenção de conhecimentos prévios & \\
\hline 3 & Organizador Prévio & \\
\hline 4 & Discussão e retomada de pontos relevantes & \\
\hline 5 & Introdução ao V de Gowin & \\
\hline 6 & Atividades com o Diagrama de Gowin & \\
\hline 1 & $\begin{array}{l}\text { Apresentação de uma situação problemática relacionada } \\
\text { com o tema }\end{array}$ & \multirow{6}{*}{ Unidade Didática (UD) } \\
\hline 2 & Proposição de problemas ou questões & \\
\hline 3 & Explicitação de respostas intuitivas ou suposições & \\
\hline 4 & Proposta das fontes de informação & \\
\hline 5 & Busca da Informação & \\
\hline 6 & Elaboração das conclusões & \\
\hline 7 & Generalização das conclusões e síntese & \\
\hline
\end{tabular}

Fonte: Adaptado de Costa (2019).

As primeiras atividades do Quadro 1 (Passos do 1 ao 6) estão relacionadas a princípios da Teoria da Aprendizagem Significativa e englobam a apresentação, obtenção dos conhecimentos prévios, organizador prévio, discussão e retomada de pontos relevantes do organizador prévio, introdução ao $\mathrm{V}$ de Gowin e atividades com o diagrama de Gowin, são atividades que apresentam o tema para os alunos, em termos de aspectos gerais, e introduzem o V de Gowin como um instrumento para o estudo de textos e experimentos.

Convém ressaltar que o $\mathrm{V}$ de Gowin é uma das alternativas para estudo e sistematização do conhecimento do aluno, frente às atividades propostas. O professor pode optar por outras alternativas, como os mapas conceituais, relatórios similares aos relatórios experimentais, entre outros. No entanto, independente da alternativa escolhida, os alunos precisam estar familiarizados com esse instrumento para dar sequência às atividades. Moreira (2006) e Valadares (2014) sugerem alguns passos que podem facilitar o primeiro contato dos alunos com o diagrama.

Na sequência, inicia-se a Unidade Didática (UD), cujas atividades são compostas por: 1) Apresentação de uma situação problemática relacionada com o tema; 2) Proposição de problemas ou questões; 3) Explicitação de respostas intuitivas ou suposições, de modo que são expostos os conteúdos relacionados ao experimento, quais os problemas que levaram a proposta do experimento, quais as possíveis respostas a esses problemas. Assim, os alunos são apresentados a um ou vários problemas que podem ser elucidados por meio da exploração da 
simulação computacional do experimento histórico. $\mathrm{O}(\mathrm{s})$ problema(s) apresentado(s) pode(m) ser relacionado(s) ao tema apresentado ou até mesmo aos desafios experimentais que precisaram ser resolvidos para a realização do experimento.

Em seguida, são desenvolvidos os passos 4, 5 e 6 da UD, nos quais são propostas as fontes de informações, é feita a busca de informações e são elaboradas as conclusões a respeito do problema a ser resolvido. Nesta parte da UD, os alunos vão explorar as simulações em busca de obter informações para resolver o(s) problema(s) proposto(s). Nesse momento, os estudantes irão receber um texto ou material alternativo (fonte de informação), para auxiliar na exploração da simulação computacional do experimento histórico (busca da informação) e como resultado da atividade, deverão elaborar um V de Gowin (elaboração das conclusões), para que eles possam registrar sua compreensão do processo de experimentação que estavam testando.

O texto que eles recebem a respeito do experimento deve conter informações teóricas que os ajudem a entender o contexto prévio do experimento, em termos de teorias, princípios e conceitos, bem como dicas para orientar a montagem do experimento na simulação computacional. Assim, o público alvo pode cruzar as informações contidas no texto com os elementos textuais da simulação e resolver os desafios impostos pela simulação. De outra forma, o texto também auxilia na elaboração do $\mathrm{V}$ de Gowin, uma vez que sua leitura é feita no tempo individual necessário para o entendimento das informações teórico-conceituais.

As atividades devem ser planejadas de forma que os alunos interajam com o recurso de maneira investigativa. Eles precisam investigar que materiais e métodos precisam utilizar para realizar o experimento, bem como interpretar resultados fictícios ou históricos para responder ao problema que o experimento se propôs a resolver.

Finaliza-se a Unidade Didática discutindo as conclusões obtidas na solução do/dos problemas e as implicações para o conteúdo científico que estava sendo estudado. Essa fase representa o passo 7 da UD, composto pela generalização das conclusões e síntese.

Como citado anteriormente, essas simulações podem ser utilizadas em conjunto ou de forma separada para tratar dos conteúdos a elas relacionados, sejam conteúdos diretamente pertinentes ao objetivo desses aparatos ou conteúdos afins, como por exemplo o tema "aceleradores de partículas". Essa terceira simulação pode ser utilizada para explicar partes do funcionamento de aceleradores de partículas, assim como a segunda simulação pode servir para exemplificar o funcionamento de uma câmara de bolhas. No entanto, sempre deve-se atentar ao fato de que as simulações foram elaboradas para serem inseridas em situações de aprendizagem previamente elaboradas, então, independentemente do conteúdo que pretende ser exemplificado com as simulações, essa atividade deve ser devidamente planejada com bases nos resultados de pesquisas em Educação Científica.

Apresentadas as três simulações, espera-se que elas possam ser úteis para exemplificação dos conteúdos a elas relacionados, sejam em aulas teóricas ou práticas de 
Física Moderna, Estrutura da Matéria ou correlatas, contribuindo na formação de futuros docentes que podem ter contato com alternativas de ensino diferenciadas.

Além disso, brevemente essas simulações estarão disponíveis para o público interessado em uma página web no site do grupo de pesquisa IFHIECEM ${ }^{4}$, que terá à disposição a Composição Histórica da Teoria Eletrofraca, bem como a sugestão de uma Abordagem Didática que foi elaborada para integrar essas simulações.

O objetivo deste trabalho é apresentar as simulações, mas, ao passo que elas foram avaliadas por pares e por usuários, convém apresentar alguns resultados. A avaliação feita por pares foi realizada por especialistas das áreas envolvidas (oito avaliadores de áreas como ensino, Física, História da Ciência e Física de Partículas e 16 avaliadores da área de Design), por meio de questionários diante da exploração das simulações. A avaliação feita por usuários se deu por meio de um questionário de opinião, que responderam após utilizarem as simulações na Abordagem Didática.

Os pares sugerem que se trata de um recurso com potencialidades para o ensino da Teoria Eletrofraca e que as simulações cumprem com o papel para o qual foram planejadas. Os usuários se sentiram motivados a explorar as simulações e que o procedimento de exploração os manteve ativos e empolgados, resultando em indícios de aprendizagem significativa, tanto em relação ao conteúdo científico quanto em relação à Natureza da Ciência. Questionados quanto à predisposição a utilizar simulações como essas, os alunos expressaram que gostariam de utilizar esse tipo de simulação novamente, seja para entender teorias, para obter uma relação entre os experimentos e a História da Ciência, por ser acessível e sem custo, por facilitar a exploração de experimentos que são difíceis ou inviáveis de montar e para utilizar na futura atuação profissional. Disso, percebe-se a predisposição dos mesmos a utilizar simulações semelhantes a essas, sendo esse um dos fatores positivos em relação às possibilidades de aprendizagem significativa de conceitos, uma vez que um dos requisitos é a predisposição dos sujeitos ao envolvimento nas situações de aprendizagem. A discussão teórico-conceitual alcançada se torna propícia para dar significado a matematizações e equacionamentos aprofundados, se também houver esse objetivo de ensino.

\section{Considerações finais}

Diante do que foi exposto neste artigo, espera-se que essas simulações possam permitir que professores e alunos tenham contato com dimensões históricas e experimentais da Teoria Eletrofraca e que elas se configurem como alternativas para o ensino e aprendizagem de tópicos de Física de Partículas no Ensino Superior.

Entende-se que elas representam fenômenos abstratos e modelados, e que, ao mesmo tempo que isso é um fator positivo, lembra-se que são modelos adaptados dos experimentos

\footnotetext{
${ }^{4}$ Grupo de Pesquisa Paranaense em História e Filosofia da Ciência, com interfaces teórico-metodológicas em Educação em Ciências e Matemática (http://www.uel.br/grupo-pesquisa/ifhiecem/).
} 
reais e que não podem ser interpretados como substitutos dos mesmos, mas sim como alternativas didáticas e acessíveis para exemplificação de processos de difícil, inviável ou impossível visualização real em sala de aula.

As experiências em sala de aula, por meio da Abordagem Didática, indicam que as simulações desempenham um papel de instigar a curiosidade dos alunos perante a resolução dos problemas, os mantém motivados perante a exploração dos experimentos e torna possível que eles explorem características experimentais e históricas de cada um dos experimentos simulados.

Trata-se de um recurso didático que foi elaborado e investigado, levando em consideração aspectos de conteúdo de ciências, de teorias da aprendizagem, da História da Ciência e de usabilidade de softwares. Uma inovação para proporcionar uma experiência positiva para estudantes e servir de instrumento de ensino e de aprendizagem de tópicos de Física Moderna Contemporânea, com potencial para gerar atividades investigativas com protagonismo estudantil, e que podem resultar em indícios de aprendizagem significativa. Alia-se, destacado nesse processo inovador, aspectos de linguagens de comunicação dos mais contemporâneos com os aspectos teórico-metodológicos da Física, da Historiografia da Ciência e da Educação Científica de modo a expressar, significativa e fidedignamente, exemplares de construção do conhecimento científico, suas idas e vindas, naturais em todas as produções humanas coletivas.

Além disso, dadas as avaliações por pares e usuários, os resultados sugerem que essas simulações cumprem com o papel para o qual foram planejadas, colaborando no aprendizado dos conteúdos, auxiliando na representação de fenômenos de difícil acesso real e permitindo que o aluno entenda o contexto histórico no qual o experimento original foi realizado. Dessa maneira, torna-se um recurso didático para o ensino de Física de Partículas.

\section{Referências}

AUSUBEL, D. P. Aquisição e retenção de conhecimentos: Uma perspectiva cognitiva. Tradução: TEODORO, V. D. 1. ed. Editora Plátano, 2003.

AZEVEDO, M. C. P. S de. Ensino por investigação: problematizando as atividades em sala de aula. In: CARVALHO, A. M. P. (Org.). Ensino de ciências: unindo a pesquisa e a prática. São Paulo: Cencage Learning, 2013.

BATISTA, I. O ensino de teorias físicas mediante uma estrutura histórico-filosófica. Ciência \& Educação, v. 10, n. 3, p. 461-476, 2004.

CARDOSO, S. O. O; DICKMAN, A. G. Simulação computacional aliada à teoria da aprendizagem significativa: uma Ferramenta para ensino e aprendizagem do efeito 
fotoelétrico. Caderno Brasileiro de Ensino de Física, v. 29, n. Especial 2, p. 891-934, out. 2012.

CARVAlHO, A. M. P. O ensino de ciências e a proposição de sequências de ensino investigativa. In: CARVALHO, A. M. P. (org.). Ensino de Ciências por Investigação: condições para implementação em sala de aula. São Paulo: Cengage Learning. 2013.

CHANG, H. How historical experiments can improve scientific knowledge and Science Education: the cases of boiling water and Electrochemistry. Science \& Education, v. 20, p. 317-341, 2011.

CLINE, D. B.; RUBBIA, C.; MEER, S. V. D. The search for intermediate vector bosons. Scientific American, v. 246, n. 3, p. 48-59, 1982.

COSTA, M. Experimentos históricos em ambiente virtual: uma abordagem históricodidática a respeito da teoria eletrofraca para o estudo de física de partículas no ensino superior. 2019. 423 f. Tese (Doutorado) - Universidade Estadual de Londrina, Londrina.

COSTA, M.; BATISTA, I. L. Abordagem histórico-didática para o ensino da Teoria Eletrofraca utilizando simulações computacionais de experimentos históricos. Caderno Brasileiro de Ensino de Física, v. 37, n. 1, p. 242-262, 2020.

DEVELAKI, M. Using Computer Simulations for Promoting Model-based Reasoning. Science \& Education, v. 26, p. 1001-1027, 2017.

FIGUEIRA, J. S. Easy Java simulations: Modelagem computacional para o ensino de Física. Revista Brasileira de Ensino de Física, v. 27, n. 4, p. 613-618, 2005.

FIOLHAIS, C.; TRINDADE, J. Física no computador: o computador como uma ferramenta no ensino e na aprendizagem das ciências físicas. Revista Brasileira de Ensino de Física, v. 25, n. 3, p. 259-272, 2003.

FORMAN, P. The fall of parity. The Physics Teacher, v. 20, n. 5, p. 281-288, 1982.

FORTES, E. C. F. S.; TIJERO, M. C.; PLEITEZ, E. V. A descoberta das correntes neutras das interações fracas. Revista Brasileira de Ensino de Física, v. 29, n. 3, p. 415-435, 2007.

GLASHOW S. L. Towards a unified theory: Threads in a tapestry. Review of Modern Physics, v. 52, n. 3, p. 539, 1980. 
GOWIN, D. B.; ALVAREZ, M. A. The art of educanting with $\mathbf{V}$ diagrams. Cambridge Universit Press, 2005.

GRECA, I. M.; SEOANE, E.; ARRIASSECQ, I. Epistemological issues concerning computer Simulations in science and their implications for science education. Science \& Education, Millsboro, v. 23, p. 879-921, 2014.

HAMMOND, R. Chien-Shiung Wu: Pioneering Nuclear Physicist. New York, 2010.

HEERING, P. Analysing unsuccessful experiments and instruments with the replication method. Éndoxa, n. 19, p. 315-40, 2005.

HEERING, P.; WITTJE, R. An historical perspective on instruments and experiments in Science Education. Science \& Education, v. 21, p. 151-155, 2012.

LEE, T. D.; YANG, C. N. Mass Degeneracy of the Heavy Mesons. Physical Review, v. 102, n. 1, p. 290-291, 1956.

MARTINS, A. J.; FIOLHAIS, C.; PAIVA, J. Simulações on-line no ensino de Física e da Química. Revista Brasileira de Informática na Educação, v.11, n. 2, 2003.

MEDEIROS, A.; MEDEIROS, C. F. de. Possibilidades e limitações das simulações computacionais no ensino da física. Revista Brasileira de Ensino de Física, São Paulo, v. 24, n. 2, p. 77-86, 2002.

METZ, D.; STINNER, A. A role for historical experiments: capturing the spirit of the itinerant lecturers of the 18th century. Science \& Education, v. 16, n. 6, p. 613-624, 2007.

MOREIRA, M. A. Mapas conceituais e diagramas V. Porto Alegre: o autor, 2006.

PICKERING A. Against putting the phenomena first: The discovery of the weak neutral current. Studies in History and Philosophy of Science Part A, v. 15, n. 2, p. 85-117, 1984.

PSYCHARIS, S. The computational experiment and its effects on approach to learning and beliefs on Physics. Computers \& Education, v. 56, p. 547-555, 2011.

RIBEIRO JUNIOR. L. A.; CUNHA, M. F.; LARANJEIRAS. C. C. Simulação de experimentos históricos no ensino de física: uma abordagem computacional das dimensões 
histórica e empírica da ciência na sala de aula. Revista Brasileira de Ensino de Física, v. 34, n. 4, 2012.

SACRISTÁN, J. G. O currículo: uma reflexão sobre a prática. Tradução: Ernani F. da Fonseca Rosa. Porto Alegre: Artmed, 2000.

SALAM, A. Gauge unification of fundamental forces. Review of Modern Physics, v. 52, n. 3, p. 525,1980 .

SAlAM, A.; DIRAC, P.; HEINSENBERG, W. Em busca da unificação. 1. ed. Lisboa: Editora Gradativa, 1991.

SMETANA, L. K.; BELL, R. L. Computer simulations to support science instruction and learning: A critical review of the literature. International Journal of Science Education, v. 34, n. 9, p. 1337-1370, 2012.

SOUZA, R. S.; SILVA, A. P. B; ARAUJO, T. S. James Prescott Joule e o equivalente mecânico do calor: reproduzindo as dificuldades do laboratório. Revista Brasileira de Ensino de Física, v. 36, n. 3, 2014.

TOVAL, A.; FLORES, M. Computer systems simulation in education: description of an experience. Computers \& Education, v. 2, n. 4, p. 293-303, 1987.

VALADARES, J. Organizadores gráficos facilitadores da Aprendizagem Significativa: Diagramas em Vê e Mapas conceituais. UIED, Coleção Educação e Desenvolvimento. 1. ed. Lisboa, Portugal, 2014.

WATKINS, P. Story of the W and Z. Cambridge University Press, 1986.

WEINBERG, S. Conceptual foundations of the unified theory of weak and electromagnetic interactions. Review of Modern Physics, v. 52, n. 3, p. 515, 1980.

WU, C. S. Parity Violation. In: NEWMAN, H. B.; YPSILANTIS, T. History of Original ideas and Basic Discoveries in Particle Physics. New York: Plenum Press, 1996.

ZABAlA, A. A Prática educativa: como ensinar. Tradução: Ernani F. da F. Rosa. Porto Alegre: Artmed, 1998. 224 p.

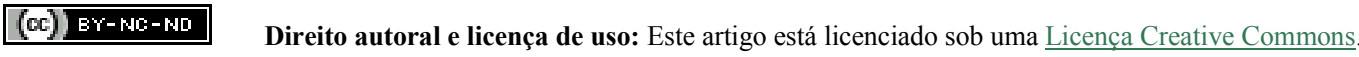

